\title{
FREQUÊNCIA DE ORDENHA: FERRAMENTA DE MANEJO E EFEITOS NA EFICIÊNCIA PRODUTIVA DE REBANHOS LEITEIROS - REVISÃO
}

\author{
LEÃO, Guilherme Fernando Mattos ${ }^{1}$ \\ SANTOS, Sthefany Kamile dos ${ }^{2}$ \\ HORST, Egon Henrique ${ }^{3}$ \\ ROZANSKI, Sandra ${ }^{4}$ \\ DURMAN, Thomer ${ }^{1}$ \\ ASKE, Eloize Jaqueline ${ }^{5}$
}

\begin{abstract}
RESUMO: O Brasil cresce a passos largos na produção de leite, e já é o quinto maior produtor do mundo. Tal fato se deve ao grande rebanho existente no país. Entretanto, no que diz respeito à produção individual, muito se tem a aperfeiçoar para que essa atividade faça frente a outras que competem com o uso da terra. Neste trabalho é apresentada uma revisão bibliográfica, discutindo a respeito da influência da frequência de ordenha sobre a glândula mamária e os aspectos reprodutivos, sanitários e econômicos analisando a viabilidade da adoção deste manejo, segundo os autores pesquisadores. A realização desse levantamento bibliográfico serviu também para mostrar que o ensejo da aplicação do maior número de ordenhas diárias é multifatorial, pois, tal mudança afetará não só a produção, mas também a sanidade da glândula mamária devido ao maior manuseio, a ingestão de matéria seca principalmente nas primeiras semanas pós-parto, e o desempenho reprodutivo das vacas. Portanto, para avaliar a viabilidade da implantação de tal manejo, alguns pontos devem ser levados em consideração, como o número de animais em lactação, o potencial produtivo dos animais, o aumento da produção com o aumento da freqüência de ordenha, o preço recebido pelo leite, além de garantir eficiência nos manejos sanitários, reprodutivos e nutricionais realizados pela propriedade.
\end{abstract}

Palavras-chave: Feedback inibidor da lactação (FIL). Reprodução. Viabilidade econômica

SUMMARY : Brazil grows with great strides in dairy production, and is the fifth largest producer in the world. This fact is due to the large herd in the country. However, with regard to individual production, much has to improve so that this activity stand up to others that compete with land use. This paper presents a bibliographical review, discussing about the influence of milking frequency on the mammary gland and the reproductive health and economic aspects analyzing the feasibility of adopting this management, according to the author's researchers. Also served to show that applying the highest number of milking per day is multifactorial, and this change will affect not only the production but also the sanity of the mammary gland due to higher handling, dry matter intake, especially in the first few weeks postpartum, and reproductive performance of cows. Therefore, to evaluate the feasibility to implement this management, some points should be taken into consideration, such as the number of animals in lactation, the productive potential of animals, the high production with increasing frequency of milking, the price received by milk, in addition to ensuring efficiency in health, reproductive and nutritional management carried out by property.

Keywords: Feedback inhibitor of lactation (FIL). Reproduction. Eeconomic feasibility

\footnotetext{
${ }^{1}$ Médico Veterinário. Mestrando do Programa de Pós-Graduação em Zootecnia. Universidade Estadual de Maringá UEM

${ }^{2}$ Médica Veterinária. Mestranda em ciências Veterinárias - Universidade Estadual do Centro Oeste - UNICENTRO

${ }^{3}$ Médico Veterinário. Mestrando em Agronomia. Universidade Estadual do Centro Oeste - UNICENTRO

${ }^{4}$ Médica Veterinária. Mestranda do Programa de Pós-Graduação em Ciência Animal. Universidade Federal do Paraná - UFPR/Setor

${ }^{5}$ Estudante de Medicina Veterinária. Universidade Estadual do Centro Oeste - UNICENTRO.
} 


\section{INTRODUÇÃO}

O Brasil é o quinto maior produtor de leite do mundo, com estimativa de crescimento linear ano a ano (IBGE, 2013). Por outro lado, a produtividade nacional ainda é considerada baixa, em função do grande número de animais ordenhados, sendo reflexo da heterogeneidade dos sistemas de produção de leite, da disponibilidade sazonal de alimentos, das falhas no manejo nutricional, reprodutivo, sanitário e de ausência de incremento produtivo para tornar a atividade sustentável (CARVALHO, 2013).

Algumas práticas são comuns no intuito de maximizar a produtividade, como o uso de aditivos em dietas e aplicação de hormônios, como a somatotropina bovina recombinante (bST). No entanto, é por meio do manejo de ordenha, que se explora a capacidade de produção, diminuem-se os problemas sanitários e permite longevidade ao animal na linha de produção (TOZZETTI et al., 2008).

A manutenção da galactopoiese depende, dentre outros fatores, da manutenção do número de células alveolares, da capacidade de síntese destas células e também da eficiência do reflexo da ejeção do leite. A ejeção do leite no momento da ordenha está relacionada à liberação de ocitocina da hipófise posterior, causando contração das células mioepiteliais dos alvéolos e ductos (COELHO, 2009). A retirada do leite estimula a lactação por diminuir o efeito inibitório da pressão intramamária, causada pelo acúmulo de leite na glândula (STRADIOTTO et al., 2010).

$\mathrm{O}$ aumento da frequência de duas para três ordenhas diárias resulta em um incremento médio de 3,5 kg de leite/vaca/dia (ERDMAN; VARNER, 1995). Porém, busca-se justificativa econômica para que o incremento na produção garanta a viabilidade da adoção deste manejo, mesmo em sistemas mais tecnificados (STELWAGEN et al., 2013). Desta forma, a análise de custos é essencial, visando gerar uma maior margem líquida final.

Com este trabalho objetiva-se revisar e destacar a influência da frequência de ordenha na glândula mamária e em aspectos reprodutivos e sanitários, analisando a viabilidade econômica da adoção deste manejo.

\section{Impacto da frequência de ordenha sobre a glândula mamária}

A glândula mamária possui uma fisiologia dinâmica. Entre as ordenhas, o leite fica estocado nos alvéolos, nos pequenos e grandes ductos e na cisterna da glândula. Somente o leite presente nos grandes ductos e cisterna da glândula está disponível para retirada imediata. O leite presente nos alvéolos e pequenos ductos estão presos por forças capilares que necessitam que a 
expulsão seja ativada, por meio da contração dos alvéolos em resposta à ligação da ocitocina às células mioepiteliais (COELHO, 2009).

A manutenção da produção do leite possui mecanismo baseado na pressão interna da glândula mamária, causada pelo leite acumulado. Se houver aumento na pressão local, ocorrerá aumento na quantidade do hormônio circulante denominado Feedback Inibidor da Lactação (FIL), que age reduzindo a síntese de leite pelas células alveolares. O aumento da frequência de ordenha proporcionaria maior esvaziamento da glândula, garantindo aumento na síntese de leite pelas células alveolares (WALL; MACFADDEN, 2011).

Embora a adoção desse manejo seja recente, a observação do acréscimo da produção atrelado ao aumento no número de ordenhas diárias, mesmo de forma empírica, tem sido notada há mais de um século (WALL; MACFADDEN, 2011). A quantificação da produção leiteira resultante do aumento da frequência de ordenha tem sido o objetivo de vários estudos, que defendem aumento de produção na ordem de 15 a $20 \%$ de duas para três ordenhas e $7 \%$ de três para quatro ordenhas diárias (STOCKDALE, 2006).

O aumento no número de ordenhas diárias, somente no período pós-parto, pode gerar acréscimo na produção leiteira de tal forma que a curva de lactação seja modificada. Isto ocorre devido ao aumento de produção no pico de lactação, e tal fato gera um efeito residual durante todo o período lactacional, aumentando inclusive a persistência da lactação (Figura 1). Tal comportamento foi verificado por diversos autores (HALE et al., 2003; DAHL et al., 2004; WALL; MCFADDEN, 2008).

Figura 1 - Comportamento da curva de lactação de vacas leiteiras ordenhadas duas ou três vezes por dia. Adaptado de Wall e McFadden (2008).

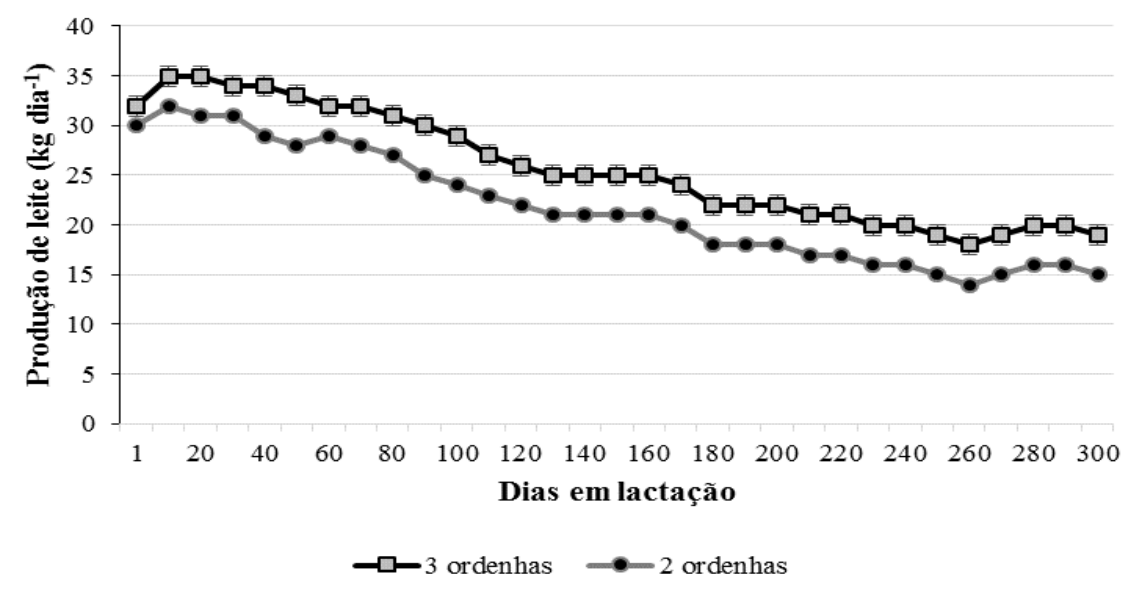

O número de ordenhas diárias tem efeito nas células da glândula mamária, na circulação sanguínea e sobre a interação hormonal. Em relação às células mamárias, existe a possibilidade do aumento da proliferação celular ou da atividade das células, ou ainda ambos. (WALL; 
MCFADDEN, 2011). Hale et al. (2003) demonstraram que há diferenças significativas na proliferação de células mamárias no período pós-parto de vacas ordenhadas quatro vezes, em contraste com vacas ordenhadas duas vezes ao dia. No entanto, é necessário outros estudos para comprovação destes não há constatação científica do aumento de qualquer um desses pontos $\mathrm{A}$ circulação sanguínea na glândula mamária, por sua vez, é inversamente proporcional à pressão do leite dentro da glândula, ou seja, quanto maior o acúmulo do leite, menor o fluxo sanguíneo local (WALL; MCFADDEN, 2011). Stelwagen et al. (1994) sugerem que há influência do FIL sobre a circulação sanguínea, uma vez que, reduzindo o fluxo sanguíneo, ocorre diminuição dos substratos para a síntese do leite em períodos de repleção da glândula mamária.

Com relação à concentração hormonal, a presença da ocitocina e prolactina são fundamentais durante o reflexo de produção e ejeção do leite. A concentração desses hormônios é maior em vacas ordenhadas mais vezes ao dia, o que se correlaciona ao estímulo galactopoiético (WALL; MCFADDEN, 2011). Os autores ainda correlacionam a ocitocina com o papel principal na inibição do FIL, e maior produção de leite com aumento na frequência de ordenhas diárias.

No entanto, há divergências em relação à aplicação exógena desses hormônios, uma vez que há trabalhos apontando a existência de efetividade da aplicação de ocitocina (LOLLIVIER; MARNET, 2005) e que não existe diferença significativa da aplicação de prolactina sobre a produção de leite (PLAUT et al., 1987).

Por outro lado, a glândula mamária fica mais propensa a problemas sanitários com o aumento da frequência da ordenha (LOISELLE et al., 2009), pois aumenta a manipulação dos tetos, com consequente exposição a agentes causadores de mastite, e desgaste físico causado pela ordenhadeira mecânica. No período pós-parto, a vaca leiteira apresenta perda exacerbada de condição corporal, desencadeando o balanço energético negativo, oriundo do baixo consumo de matéria seca. Vacas ordenhadas mais vezes ao dia, tendem ao maior direcionamento de nutrientes para a produção de leite, deixando o sistema imune deficiente (CHAMBELA NETO et al., 2011).

Mastite, doenças podais, estresse calórico e desordens metabólicas podem ser mais frequentes em animais ordenhados mais vezes ao dia (STELWAGEN et al., 2013). No entanto, há trabalhos que contradizem tal fato, e ressaltam que não há influência da frequência diária de ordenha sobre a sanidade da glândula mamária (RUAS et al., 2006). O’Driscoll et al. (2012) verificaram que vacas menos vezes ordenhadas durante o dia, possuem melhores perfis imunes. Em relação à contagem de células somáticas, os resultados em literatura tem sido inconstantes (WALL; MACFADDEN, 2007).

O aumento no número de ordenhas diárias pode ser utilizado em sistemas de vacas de alta produção, que tenham o manejo nutricional eficiente. Essa prática deve ser realizada 
simultaneamente com o aumento do concentrado em dieta balanceada, de forma que os efeitos do balanço energético negativo, natural para este estágio lactacional, não se agravem. O aumento de concentrado pode representar um custo a mais no sistema de produção de leite, devendo ser analisada, portanto, a viabilidade econômica desse manejo (RUAS, et al., 2006).

Por outro lado, sistemas extensivos, primordialmente baseados no consumo de pastagens, a redução da frequência de ordenha diária pode ser a opção mais adequada, além de ser interessante por minimizar os problemas sanitários neste tipo de produção (STELWAGEN et al., 2013). Além disto, pode representar uma característica econômica relevante, por diminuir o manejo na propriedade e os custos com mão-de-obra.

Todavia, a redução da frequência de ordenha diária, compromete bruscamente a produção leiteira e a curva de lactação. Stelwagen et al. (2013) constataram que a redução resulta em uma diminuição média de produção na ordem de $22 \%$, variando consideravelmente com a raça, o estágio de lactação e a ordem de parto.

Clark et al. (2006), demonstraram que vacas da raça Jersey possuem menores perdas de produção em relação a vacas da raça holandesa, em virtude da menor produção leiteira. No início de lactação, as perdas em produção são maiores quando comparadas à outras fases da lactação, pois o pico lactacional não será potencializado, e consequentemente a persistência de lactação dessas vacas, com a ordenha reduzida, será menor. Já comparando a ordem de parto, vacas primíparas entrando em regime de uma ordenha por dia possuem maiores perdas, quando comparadas com vacas multíparas em mesmo manejo (SANTOS, et al., 2002).

Stelwagen et al. (2013) ressaltaram que animais submetidos a uma ordenha diária, possuem altos índices de células somáticas, mesmo sem ocorrência de mastite, justificando-se pelo fato de que animais ordenhados uma vez ao dia, acabarem acumulando células naturais de descamação, gerando um índice maior.

\section{Frequência de ordenha e sua correlação com a composição do leite}

A produção e a composição do leite podem ser influenciadas pela adoção de diversas práticas, dentre elas destacam-se o melhoramento genético, as mudanças nutricionais, o ambiente e o conforto, os tratamentos hormonais, e o aumento no número diário de ordenhas (LIMA et al., 2011). Animais ordenhados uma vez ao dia possuem aumento relativo de gordura e proteína, enquanto a lactose apresenta um decréscimo na composição do leite (STELWAGEN et al., 2013).

No entanto, esse aumento relativo não é considerado, uma vez que, devido ao menor volume de leite produzido, ocorre o efeito de concentração de gordura e proteína. Phyn et al. (2008) citam que o aumento da frequência de ordenha por um curto período, no início da 
lactação, pode resultar em melhorias a longo prazo na produção de leite, mas não em relação à produção de sólidos.

Isso concorda com os resultados de Lovendahl et al. (2011) que demonstraram que vacas ordenhadas com maior frequência durante toda a lactação, acabam por possuir maiores percentuais de gordura nos períodos de decréscimo da produção.

Este achado foi verificado também no estudo de Lima et al. (2011), no qual os valores de proteína não foram influenciados pelo aumento da frequência de ordenhas, e os grupos com quatro ordenhas diárias apresentaram maior teor de gordura no leite nos primeiros 21 dias de lactação. A justificativa segundo os autores pode estar associada à baixa produção média observada nos animais dos dois grupos (17,97 litros dia $\left.{ }^{-1}\right)$, e também pelo aumento no número de células e atividade enzimática no início da lactação, fato este também proposto por Hale et al. (2003). Portanto, a produção absoluta de sólidos é menor nos sistemas com frequência de ordenha reduzida.

Os menores teores de sólidos geram menor aproveitamento industrial, na produção de derivados lácteos. No entanto, Pomiès et al. (2007) atribuíram que a menor quantidade de gordura em leite de vacas submetidas a regime de uma ordenha diária é benéfica para a produção de manteiga e creme industrializados. Com relação à palatabilidade, Martin et al. (2009) demonstraram que não houve diferença significativa de análise sensorial entre leites oriundos de sistemas com uma e duas ordenhas diárias.

A composição do leite é variável com o período da ordenha durante o dia. Em trabalho realizado por Fava et al. (2011) avaliando o efeito de três ordenhas na composição do leite, os autores verificaram que a lactose e a proteína não variaram nos turnos estudados, embora sendo os níveis de lactose superiores no período matutino. A gordura foi o componente mais variável, apresentando o maior teor na ordenha noturna. Isso justifica-se pela maior produção leiteira no período matutino, com elevação na porcentagem de lactose e concomitantemente, diluição da quantidade de gordura.

\section{Impactos da frequência de ordenha sobre a reprodução}

O possível antagonismo entre alta produção leiteira e desempenho reprodutivo é um dos principais temas debatidos entre produtores de leite e pesquisadores (LEBLANC, 2010). Segundo Blevins et al. (2006), vacas ordenhadas em maior número de vezes ao dia possuem intervalo mais longo para o primeiro cio. Além disto, a alta produtividade piora o desempenho reprodutivo, e o aumento da frequência de ordenha é um fator catalisador desse problema (SARTORI; GUARDIEIRO, 2010). 
Segundo Vieira (2010), a primeira ovulação no período pós-parto é fundamental para obter a eficiência reprodutiva, e a nutrição contribui tanto para a manifestação do estro, como para a inatividade ovariana. Sendo assim, Wiltbank et al. (2006) citam que o atraso na primeira ovulação pós-parto, é atribuída ao período de balanço energético negativo e a diminuição dos pulsos de LH.

Animais com elevado potencial de produtividade, apresentam acentuado balanço energético negativo (BEN) no início de lactação, resultando intensa mobilização dos tecidos corporais para atender as exigências de mantença e produção, ocasionando a queda da condição corporal (LOISELLE et al., 2009). Assim, o erro no balanço entre as exigências do animal e a disponibilidade de nutrientes terá efeito primeiramente na reprodução (OLIVEIRA; CHRISTOVÃO, 2012).

Quando as vacas estão em balanço energético negativo, as concentrações sanguíneas de ácidos graxos não esterificados, uréia e $\beta$-hidroxibutirato aumentam, enquanto as concentrações de fator de crescimento do tipo insulina I (IGF-I), glicose e insulina estão baixas devido à produção de leite (SARTORI; GUARDIEIRO, 2010). Segundo os mesmos autores, essa alteração nos níveis sanguíneos dessas substâncias está geralmente associada ao comprometimento da função ovariana e fertilidade.

Leroy et al. (2010) citam que os folículos primários expostos a condições adversas, associados com o período crítico do BEN, podem produzir quantidades inferiores do ideal, de estrogênio e progesterona após a ovulação, e esses folículos estariam mais predispostos a conter um oócito de qualidade inferior.

Segundo Brandão et al. (2007), os animais ordenhados três vezes ao dia tendem a perder mais peso, comparados aos animais com duas ordenhas diárias, sugerindo a ocorrência de processos catabólicos para a manutenção da produção de leite. Assim, infere-se que o BEN nesses animais é mais acentuado, e, por conseguinte, terá o efeito prejudicial potencializado na reprodução.

Em pesquisa realizada por Wiltbank et al. (2006) foi verificado que vacas com produção leiteira acima da média do rebanho, tiveram menor duração do estro quando comparadas à vacas com produção leiteira inferior, bem como, produziram folículos e corpo lúteo maiores, porém obtiveram menor concentração de estradiol e progesterona circulantes.

A justificativa mais aceita para esses achados paradoxais é o aumento do metabolismo dos hormônios esteróides quanto maior a produção de leite, em vacas lactantes, o que é decorrente do contínuo consumo elevado de alimentos a qual esses animais estão submetidos. Isto eleva o fluxo sanguíneo hepático, e aumenta o metabolismo de hormônios esteroides para aproximadamente o 
dobro da quantidade observada em vacas não lactantes, de tamanho e idade semelhantes (WILTBANK et al., 2006).

Assim, as alterações metabólicas decorrentes do BEN, e as menores concentrações de hormônios esteróides circulantes, favorecem a ocorrência do anestro pós-parto, ou o aparecimento de estros silenciosos, pois as alterações comportamentais e fisiológicas características do cio são dependentes de esteroides (BERGAMASCHI; VICENTE, 2010).

Contudo, Lima et al. (2011) em seu experimento avaliando animais em sistema de duas ou quatro ordenha diárias, durante os primeiros 21 dias de lactação, observaram que todas as vacas ficaram gestantes, mostrando que o número de cobrições e o período de serviço não foram influenciados pelo número de ordenha.

Por outro lado, a redução do número de ordenhas diárias, seria um manejo aceitável para melhorar as taxas de prenhez, com diminuição do anestro pós-parto. Assim, haveria diminuição dos gastos com a adoção de protocolos de inseminação artificial em tempo fixo, o que diminuiria, por consequência, os custos de todo o sistema produtivo. $\mathrm{O}$ desempenho reprodutivo superior é justificado pela minimização dos efeitos deletérios do balanço energético negativo, o que acontece devido ao menor número de ordenhas realizadas diariamente (STELWAGEN et al., 2013).

McNamara et al. (2008), estudando se uma menor frequência de ordenha nas quatro primeiras semanas de lactação poderia resultar em BEN menos acentuado, e melhorar o status metabólico e os índices de fertilidade, verificaram que a redução de duas para uma ordenha diária no início da lactação, reduziu a perda de peso corporal e escore corporal. Os autores não encontraram diferença estatística nas variáveis reprodutivas analisadas, mas perceberam que vacas que conceberam no primeiro serviço estavam em maior balanço energético positivo nas primeiras seis semanas de lactação.

Contudo, apesar da aparente melhora nos índices reprodutivos conforme a redução da frequência de ordenha, a diminuição na produção de leite diária e produção total é a observação mais comum e consistente nas vacas ordenhadas apenas uma vez ao dia (PHYN et al., 2010). Assim, deve ser demonstrada relação mais direta entre a diminuição da frequência de ordenha no início da lactação e melhora na fertilidade, antes que essa estratégia esteja mais susceptível de ser utilizada na prática (MCNAMARA et al., 2008).

\section{Viabilidade econômica}

Independentemente da produção, qualquer atividade agropecuária deve ser lucrativa e sustentável, viabilizando qualquer tomada de decisão subsequente. No caso do aumento da 
frequência de ordenha diária, a produção de leite adicional é acompanhada por aumento no custo alimentar e custo operacional da hora/ordenha, além de outros fatores a ser considerados como o tamanho e saúde do rebanho, e principalmente o preço pago pelo leite (MALTZ et al., 2003). Segundo Erdman \& Varner (1995) a adoção de uma ordenha extra, acarreta aumento dos gastos principalmente com mão de obra, maquinário e implementos utilizados na ordenha, como soluções desinfetantes, papel toalha, água, alimentação, entre outros.

O custo de produção apresenta grande variação entre propriedades de exploração leiteira, no entanto, diversos trabalhos verificaram a viabilidade econômica da adoção do aumento da frequência de ordenha. Wall e McFadden (2007) estimaram aumento do lucro líquido em cerca de U\$ 93,00 por vaca ao ano, quando ordenhadas quatro vezes ao dia nas primeiras três semanas da lactação e retornando posteriormente a duas ordenhas diárias.

Soberón (2008), por sua vez, realizou análise econômica para pequenos e grandes rebanhos norte-americanos, comparando a rentabilidade de vacas submetidas a duas, três e quatro ordenhas diárias ao longo de toda lactação. Foi demonstrado que para pequenos rebanhos (200 vacas em lactação) ordenhar quatro vezes ao dia durante o início da lactação, com subsequente retorno a duas ordenhas é mais rentável do que duas ou três ordenhas ao longo de toda lactação. Para grandes rebanhos (1.000 vacas em lactação) o manejo de ordenha mais adequado economicamente seria o de três ordenhas diárias.

Com relação a trabalhos brasileiros, Lima et al. (2011) analisaram a viabilidade da quarta ordenha diária nos primeiros 21 dias de lactação de animais mestiços Holandês x Zebu, e perceberam que as vacas produziram em média 2 litros a mais de leite, o que resultou num incremento da renda de 17,3\% sobre a margem bruta estimada com a venda da produção de leite.

Barbosa et al. (2013) estimaram o custo de uma e três ordenhas, desenvolvendo uma equação matemática (Figura 2) que permitiu presumir a quantidade mínima de leite produzido com duas ordenhas diárias que viabilizasse a terceira. Tal ferramenta, por mais simplista que seja,

Figura 2 - Equação descritiva confrontando a produção mínima de leite para a adoção da terceira ordenha em um sistema de produção de leite. Onde:

$$
P M=\frac{\left(P F+\frac{C O}{P L-C V}\right)}{Q A} X \frac{P F}{P F+A P}
$$

pode ser referência prática na adoção efetiva de três ordenhas.

$\mathrm{PM}=$ produção mínima de leite vaca.dia ${ }^{-1}$ desejada para tornar a terceira ordenha economicamente viável, em kg;

$\mathrm{PF}=$ produção de leite.dia ${ }^{-1}$ da fazenda, em kg;

$\mathrm{CO}=$ custo operacional total da terceira ordenha, em R\$;

$\mathrm{PL}=$ preço recebido por $\mathrm{kg}$ de leite, em $\mathrm{R} \$$ 
$\mathrm{CV}=$ custo variável de um $\mathrm{kg}$ de leite, em $\mathrm{R} \$$;

$\mathrm{QA}=$ quantidade de animais ordenhados por dia;

$\mathrm{AP}=$ aumento da produção diária de leite $\cdot \mathrm{dia}^{-1}, \mathrm{em} \mathrm{kg}$, com a terceira ordenha .

Fonte: Barbosa et al. (2013)

Por fim, é notória a maior lucratividade obtida com o aumento da frequiência de ordenhas, pois, com ela aumenta-se a produção de leite e em muitos casos a produção de gordura. Porém, a viabilidade dessa prática é questionada ao analisar as quedas reprodutivas e a maior susceptibilidade a problemas sanitários que a mesma pode ocasionar num rebanho.

Assim, a viabilidade do aumento do número de ordenhas diárias deve ser analisada caso a caso, levando em consideração o número de animais em lactação, o potencial produtivo do rebanho, o aumento da produção com o aumento da freqüência de ordenha, o preço recebido pelo leite, além de garantir eficiência nos manejos sanitários, reprodutivos e nutricionais realizados na propriedade.

\section{CONSIDERAÇÕES FINAIS}

O maior número de ordenhas vem se tornando manejo atrativo para algumas propriedades, pois aumenta-se a produção e, por conseguinte, a lucratividade. Além da possibilidade de determinar com maior precisão, a real eficiência produtiva dos rebanhos leiteiros.

Porém, para se obter sucesso, a produção não deve ser considerada isoladamente, e vários pontos precisam ser levados em consideração para a adoção de tal manejo, como desempenho reprodutivo, sanidade animal, disponibilidade de mão de obra, entre outros.

De maneira geral, o que tem se descrito na literatura é que tal prática se torna viável na maioria das vezes, para grandes propriedades e inviável para pequenas.

\section{REFERÊNCIAS}

BARBOSA, G.L.et al.Viabilidade Econômica da terceira ordenha em sistemas de produção de leite com ordenhadeira tipo circuito aberto. Arquivo Brasileiro de Medicina Veterinária e Zootecnia, Belo Horizonte, v.65, p.1123-1130, 2013

BLEVIS, C.A.; SHIRLEY, J.E.; STEVENSON, J.S. Milking frequency, estradiol cypionate, and somatotropin influence lactation and reproduction in Dairy Cows. Journal of Dairy Science, Savoy, v.89, p.4176-4187, 2006. 
CARVALHO, I. Q. 2013. Tecnologia da produção de silagem de milho em sistemas de produção de leite. Programa de Pós Graduação em Zootecnia.96p. Universidade Estadual de Maringá. Maringá, 2013.

CHAMBELA NETO, A.et al. Problemas metabólicos provenientes do manejo nutricional incorreto em vacas leiteiras de alta produção recém paridas. Revista Electrónica de Veterinaria, v.12, p.1-25, 2011.

CLARK, D.A.et al. A systems comparison of once- versus twice-daily milking of pastured dairy cows. Journal of Dairy Science, Savoy, v.89, p.1854-1862, 2006.

COELHO, S.G. Glândula Mamária e Lactação. In: Manejo e Administração na Bovinocultura Leiteira. $1^{\text {a }}$ Ed. Viçosa, p.91-110, 2009.

DAHL, G.E.et al. Effects of frequent milking in early lactation on milk yield and udder health. Journal of Dairy Science, Savoy, v.87, p.882-885, 2004.

FAVA, L.W.; GUIMARAES, T.G.; PINTO, A.T. Efeito de três ordenhas diárias sobre a composição do leite de vacas da raça Holandês. Acta Scientiae Veterinariae, Porto Alegre, v.39, p.998, 2011.

HALE, S.A.; CAPUCO, A.V.; ERDMAN, R.A. Milk yield and mammary growth effects due to increased milking frequency during early lactation. Journal of Dairy Science, Savoy, v.86, p.2061-2071, 2003.

IBGE - Instituto Brasileiro de Geografia e Estatística. 2013. Indicadores: Estatística da produção pecuária.

<http://www.ibge.gov.br/home/estatistica/indicadores/agropecuaria/producaoagropecuaria/abateleite-couro-ovos_201402_publ_completa.pdf > Acesso em 14 de Outubro de 2014.

LIMA, J.A.M.et al. Viabilidade financeira da utilização de quatro ordenhas nos primeiros 21 dias da lactação de vacas mestiças F1 Holandês/Zebu. Arquivo Brasileiro de Medicina Veterinária e Zootecnia, Belo Horizonte, v.63, p.408-413, 2011.

LOISELLE, M.C.et al. Impact of postpartum milking frequency on the immune system and the blood metabolite concentration of dairy cows. Journal of Dairy Science, Savoy, v.92, p.19001912, 2009.

LOLLIVIER, V. AND MARNET, P. Galactopoietic effect of milking in lactating Holstein cows: Role of physiological doses of oxytocin. Livestock Production Science, v.95, p.131-142, 2005.

LOVENDAHL, P.; CHAGUNDA, M.G.G. Covariace among milking frequency, milk yield and milk composition from automatically milked cows. Journal of Dairy Science, Savoy, v.94, p.5381-5392, 2011.

MALTZ, E.; LIVSHIN, N.; ANTLER, A. Variable milking frequency in large dairies: Performance and economic analysis - Models and experiments. Livestock Production Science, v.1, p.113-118, 2003.

MARTIN, B.et al. Yield and sensory properties of cheese made with milk from Holstein or Montbeliarde cows milked twice or once daily. Journal of Dairy Science, Savoy, v.92, p.4720 4730, 2009. 
O'DRISCOLL, K.et al. Reduction in milking frequency and feed allowance improves dairy cow immune status. Journal of Dairy Science, Savoy, v.95, p.1177-1187, 2012.

PLAUT, K.et al. Effect of exogenous prolactin administration on lactational performance of dairy cows. Domestic Animal Endocrinology, v.4, p.279-290, 1987.

RUAS, J.R.M.et al. Influência da frequência de ordenhas diárias sobre a eficiência produtiva de vacas mestiça Holandês-Zebu e o desempenho de seus bezerros. Revista Brasileira de Zootecnia, Viçosa, v.35, p.428-434, 2006.

SANTOS, G.T.; DAMASCENO, J.C.; MASSUDA, E.M. Importância do manejo e considerações econômicas na criação de bezerras e novilhas. In: Anais do II Sul-Leite: Simpósio sobre Sustentabilidade da Pecuária Leiteira na Região Sul do Brasil, Toledo-PR. 212 p., 2002.

ERDMAN, R.A. AND VARNER, M. Fixed yield responses to increased milking frequency. Journal of Dairy Science, Savoy, v.78, p.1199-1203, 1995.

SARTORI, R.; GUARDIEIRO, M.M. Fatores nutricionais associados à reprodução da fêmea bovina. Revista Brasileira de Zootecnia, Viçosa, v.39, p.422-432, 2010.

SOBERÓN, F. Effect of increased milking frequency during early lactation on performance, metabolism, and mammary cell proliferation of dairy cows. Dissertação (Mestrado em Ciência) - Cornell University, Ithaca, NY, 101p., 2008.

STELWAGEN, K.et al. Effect of once daily milking and concurrent somatotropin on milk production and mammary tight junction permeability in cows. Journal of Dairy Science, Savoy, v.77, p.2994-3001, 1994.

STELWAGEN, K.; PHYN, C.V.C.; DAVIS, S.R.; GUINARD-FLAMENT, J.; POMIÈS, D.; ROCHE, J.R.; KAY, J.K. Invited Review: Reduced milking frequency: Milk production and management implications. Journal of Dairy Science, Savoy, v.96, p.3401-3413, 2013.

STOCKDALE, C. R. Influence of milking frequency on the productivity of dairy cows. Australian Journal of Experimental Agriculture, v.46, p.965-974, 2006.

STRADIOTTO, M.M.et al. Efeito da gordura protegida sobre a produção e composição do leite em ovelhas da raça Bergamácia. Revista Brasileira de Zootecnia, Viçosa, v.39, p.1154-1160, 2010 .

WALL, E. H.; MCFADDEN, T. B. The milk yield response to frequent milking in early lactation of dairy cows is locally regulated. Journal of Animal Science, Champaign, v.90, p.716-720, 2007.

WALL, E. H.; MCFADDEN, T. B. Use it or lose it: Enhancing milk production efficiency by frequent milking of dairy cow. Journal of Animal Science, Champaign, v.86, p.27-36, 2008.

WALL, E. H.; MCFADDEN, T.B. A local affair: How the mammary gland adapts to changes in milking frequency. Journal of Animal Science, Champaign, v.90, p.1695-1707, 2011. 